OPEN ACCESS

Edited by:

Chi Wei Su,

Qingdao University, China

Reviewed by:

Wei Zhou,

Yunnan University of Finance and

Economics, China

Xunjie Gou,

University of Granada, Spain

${ }^{*}$ Correspondence:

Weike Zhang

zhangwk@scu.edu.cn

Specialty section:

This article was submitted to

Health Economics,

a section of the journal

Frontiers in Public Health

Received: 28 February 2021

Accepted: 31 March 2021

Published: 04 May 2021

Citation:

Bai $P$, Tang $Y$, Zhang $W$ and Zeng $M$ (2021) Does Economic Policy

Uncertainty Matter for Healthcare Expenditure in China? A Spatial

Econometric Analysis.

Front. Public Health 9:673778.

doi: 10.3389/fpubh.2021.673778

\section{Does Economic Policy Uncertainty Matter for Healthcare Expenditure in China? A Spatial Econometric Analysis}

\author{
Pu Bai ${ }^{1}$, Yixuan Tang ${ }^{2}$, Weike Zhang ${ }^{2 \star}$ and Ming Zeng ${ }^{2}$ \\ ${ }^{1}$ Carey Business School, Johns Hopkins University, Baltimore, MD, United States, ${ }^{2}$ School of Public Administration, Sichuan \\ University, Chengdu, China
}

A growing body of research has documented the determinants of healthcare expenditure, but no known empirical research has focused on investigating the spatial effects between economic policy uncertainty (EPU) and healthcare expenditure. This study aims to explore the spatial effects of EPU on healthcare expenditure using the panel data of 29 regions in China from 2007 to 2017. Our findings show that healthcare expenditure in China has the characteristics of spatial clustering and spatial spillover effects. Our study also shows that EPU has positive spatial spillover effects on healthcare expenditure in China; that is, EPU affects not only local healthcare expenditure but also that in other geographically close or economically connected regions. Our study further indicates that the spatial spillover effects of EPU on healthcare expenditure only exist in the eastern area. The findings of this research provide some key implications for policymakers in emerging markets.

Keywords: economic policy uncertainty, healthcare expenditures, spatial spillover effects, spatial Durbin model, regional heterogeneity

\section{INTRODUCTION}

Healthcare expenditure has increased rapidly with the development of China's economy in the past few decades. According to the National Bureau of Statistics of China, the ratio of total health expenditures to gross domestic product (GDP) increases from $4.57 \%$ in 2008 to $6.67 \%$ in $2019^{1}$. As shown in Figure 1, the per capita expenditures on health rose from 393.80 RMB in 2001 to 4,702.79 RMB in 2019, suggesting that the Chinese government increased funding to construct a more sustainable system that covers the health needs of most or all citizens. However, the growth rate of per capita expenditure on health fluctuates from $8.82 \%$ in 2000 to $10.99 \%$ in 2019, and it reaches a peak of $24.94 \%$ during the global financial crisis in 2008 . These results indicate that health expenditure changes with economic growth and policies $(1,2)$.

In recent years, a large and growing body of literature has investigated the determinants of healthcare expenditure, such as business cycles (2), economic overheating (3), economic activity (4), economic crisis $(1,5)$, and other factors $(6-10)$. The most studied determinant is economic growth, which is an important demand-side driver of healthcare expenditure $(2,11,12)$. Some studies show that healthcare expenditure is significantly positive with GDP because the demand for healthcare services will rise with the increase of income $(4,11,13)$.

${ }^{1}$ Data source: https://data.stats.gov.cn 


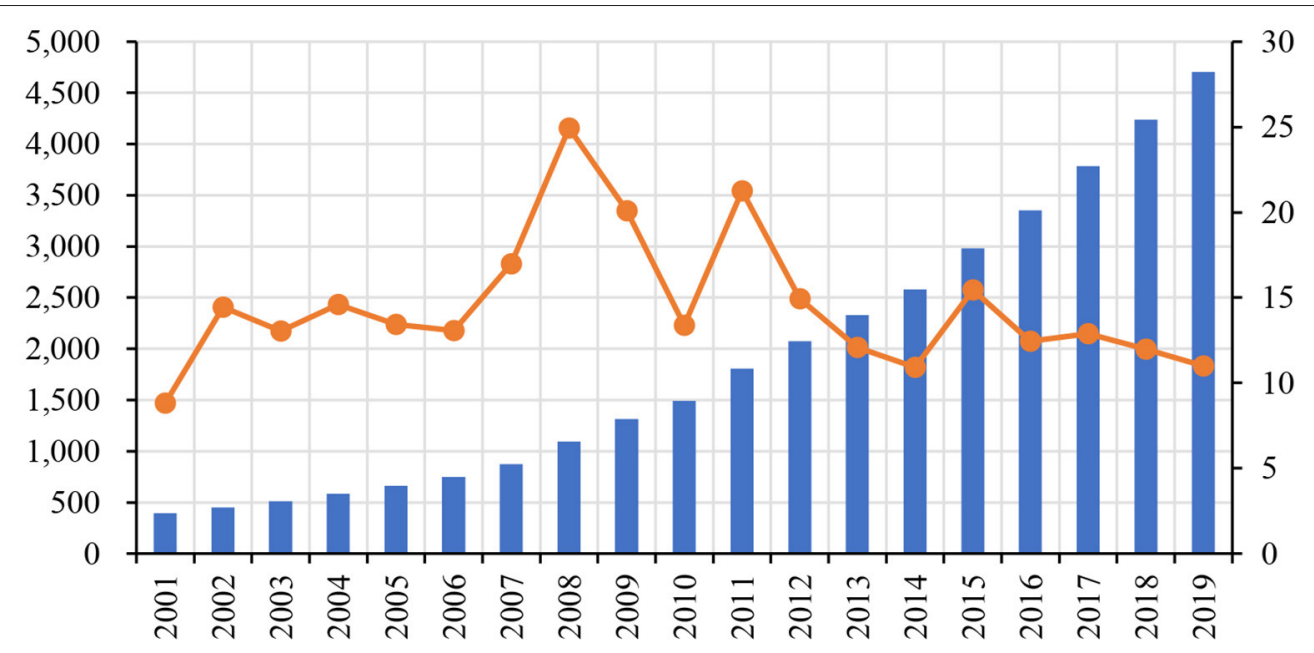

Per capita expenditure on health (RMB)(Left vertical axis)

- Growth rate of per capita expenditure on health (\%)(Right vertical axis)

FIGURE 1 | The trend of per capita expenditure on health in China (2000-2019). Data source: National Bureau of Statistics of China (https://data.stats.gov.cn).

Furthermore, some studies find that other macroeconomic factors can also affect healthcare expenditure. For example, You and Okunade (14) state that technological changes and income are the major determinants of healthcare expenditure. Hyun et al. (15) find that population aging has a significant impact on healthcare expenditure but the conclusions are mixed.

In addition to the factors above, government policies have a key role in determining healthcare expenditure (11). Some studies show that governments can influence healthcare expenditure by formulating health policies to meet their objectives (16-18). For example, Cheng and Witvorapong (11) find that health policy uncertainty exerts a negative impact on health expenditures. Potrafke (19) investigates the impact of electoral motives on public healthcare expenditure using the data of 18 OECD countries and shows that the public healthcare expenditure increase significantly before election year for political opportunism of the incumbent government. These studies suggest that governments' health policies can affect healthcare expenditure, but the policies are uncertain and may be unpredictable at all. Economic policy uncertainty (henceforth EPU) represents the uncertainty of macroeconomic policies (20). The rise or fall of EPU has an impact on the economy and may prompt demanders and suppliers in the healthcare services market to respond in ways that policymakers cannot foresee $(11,21-23)$. Up to now, however, far too little attention has been paid to investigate the impact of EPU on healthcare expenditure in emerging market countries.

This study, therefore, set out to assess the spatial spillover effects of EPU on healthcare expenditure in China. The main contributions of this study are presented in two aspects. First, this study sheds new light on the impact of EPU on healthcare expenditure in China. To the best of our knowledge, only Cheng and Witvorapong (11) examine the link between health economic policy uncertainty and healthcare expenditure in the United States. However, unlike developed economies in Europe and the United States, China's health system is dominated by the government, which has great power to allocate resources directly (23-25). Hence, this study makes a major contribution to research on health economics by demonstrating the relationship between EPU and healthcare expenditure in emerging markets. Second, the importance and originality of this study are that it explores the spatial spillover effects of EPU on healthcare expenditure and their regional heterogeneity. To date, previous studies have failed to examine the spatial spillover effects between them. However, different regions are not independent of each other, and various economic activities in one region may affect economic activities in other regions $(26,27)$. If we ignore the spatial effects when analyzing the link between EPU and healthcare expenditure, the conclusion may be inaccurate. Therefore, we offer new empirical evidence on whether EPU has spatial spillover effects on healthcare expenditure in China. Our findings have some key implications for policymakers in emerging markets.

The remaining part of this study proceeds as follows: Section Data, variables and methods develops our research design, including data, variables, and methods. Section Spatial autocorrelation analysis presents the results of spatial autocorrelation analysis. Section Empirical analysis and discussion gives our empirical analysis and discussions. The final section concludes our research results. 

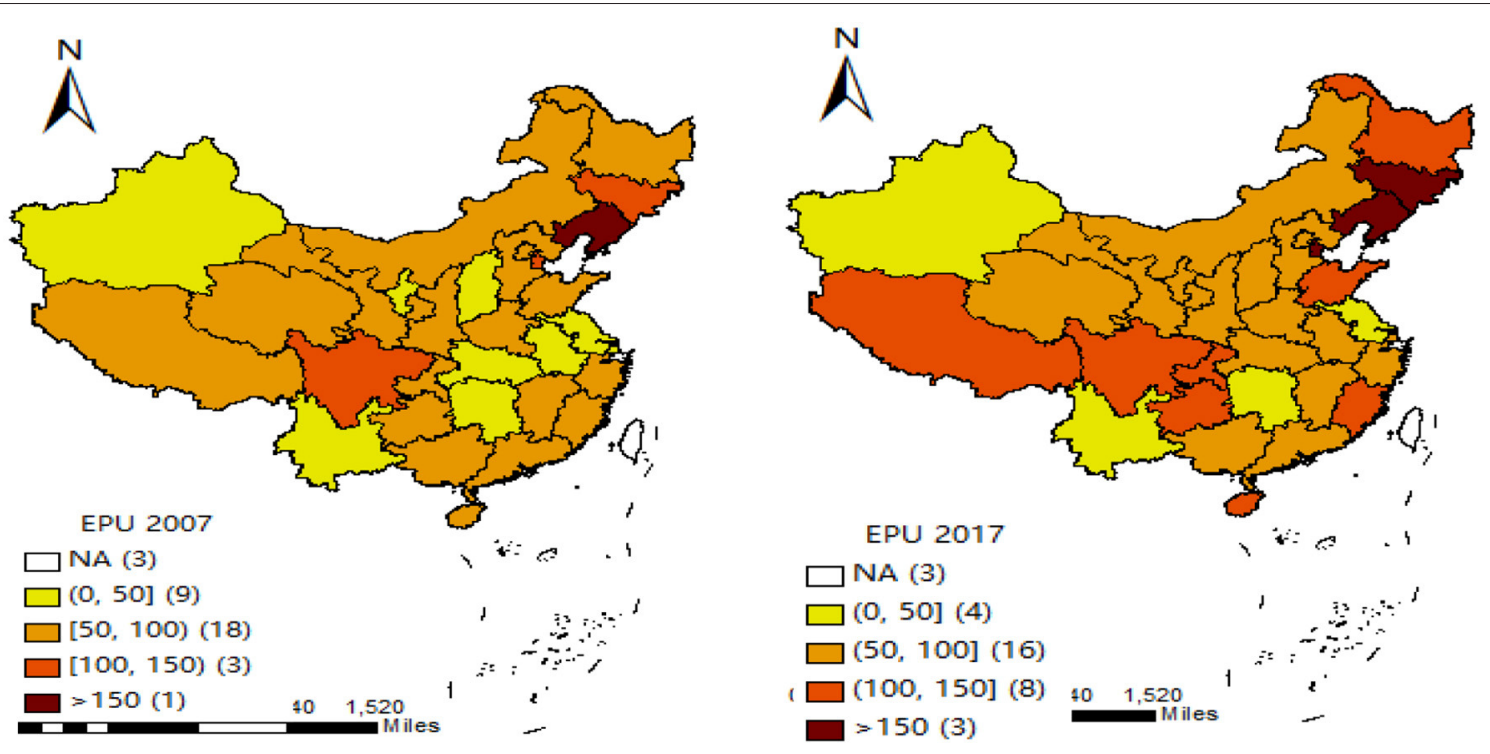

FIGURE 2 | Distribution of the provincial EPU index in China (2007 and 2017).

\section{DATA, VARIABLES, AND METHODS Data}

This study selects a sample of 29 regions in China from 2007 to 2017 to examine the spatial effects of EPU on healthcare expenditure. The samples include Beijing, Tianjin, Hebei, Shanxi, Inner Mongolia, Liaoning, Jilin, Heilongjiang, Shanghai, Jiangsu, Zhejiang, Anhui, Fujian, Jiangxi, Shandong, Henan, Hubei, Hunan, Guangdong, Guangxi, Chongqing, Sichuan, Guizhou, Yunnan, Shaanxi, Gansu, Qinghai, Ningxia, and Xinjiang. The data of EPU are selected from the EPU index proposed by $\mathrm{Yu}$ et al. (28). The data of inpatient expenditure and outpatient expenditure are collected from the China Health Statistics Yearbook 20082018. The other data are collected from the Chinese Statistics Yearbook 2008-2018.

\section{Variables}

\section{Dependent Variable: Healthcare Expenditure}

Healthcare expenditure is one of the important indicators of residents' health status. Healthcare expenditure is used to measure the final consumption of healthcare goods and services, including personal healthcare (i.e., therapeutic care, rehabilitation care, long-term care, ancillary services, and medical goods) and collective services (i.e., prevention and public health services). In this study, following the studies of $\mathrm{Pu}$ et al. (2) and Zeng et al. (27), we use the inpatient expenditure (in_exp) as the proxy variable of healthcare expenditure, which refers to the logarithm of the per capita expenditure in hospitalization. Also, we use outpatient expenditure (out_exp) for the robustness test, which is expressed as the logarithm of the per capita expenditure in outpatient (27).

\section{Independent Variable: EPU}

The prior studies mainly use many proxy variables to measure EPU. For example, the single economic policy variables (2932), the non-economic dummy variables (i.e., terrorist attacks and political events) (33-35), the EPU index proposed by Baker et al. (20) (BBI index) (23, 36-38). Since the measures above on EPU are mainly at the national level, the EPU of different regions in China may be different. Hence, we measure the provincial EPU (EPU1) using the EPU index proposed by $\mathrm{Yu}$ et al. (28). Besides, we use the standardization of China's provincial EPU index (EPU2) to conduct a robustness test. Figure 2 gives the distribution of China's provincial EPU index in 2007 and 2017. They show that the EPU index of different regions in China has obvious dynamic change characteristics and significant differences. For example, in 2007, the EPU index of Liaoning province is the highest, and that of Jiangsu province is the lowest. However, in 2017, the region with the highest EPU index is Shanxi province, and that with the lowest is Heilongjiang province.

\section{Control Variables}

According to the determinants published by the World Health Organization (WHO), many factors would affect healthcare expenditure. Following the study of Zeng et al. (27), we control the following variables: economic development (GDP), aging rate (Aging_rate), urbanization level (Urban_rate), industrial structure (Indu_rate), the mortality rate (Mor_rate), the number of medical institutions (Hos_num), fiscal revenue (Fiscal_rev), and the number of per capita beds in medical institutions (Bed_num). The economic development is measured by the logarithm of gross domestic product (GDP). The aging rate is measured by the ratio of people over 65 to the total population. The urbanization level is measured by the ratio of the urban population to the total population. The industrial structure 
TABLE 1 | Description of the variables.

\begin{tabular}{|c|c|c|c|}
\hline Types & Variables & Symbols & Definitions \\
\hline \multirow[t]{2}{*}{$\begin{array}{l}\text { Dependent } \\
\text { variables }\end{array}$} & $\begin{array}{l}\text { Inpatient } \\
\text { expenditure }\end{array}$ & In_exp & $\begin{array}{l}\text { The logarithm of the per capita } \\
\text { expenditure in hospitalization }\end{array}$ \\
\hline & $\begin{array}{l}\text { Outpatient } \\
\text { expenditure }\end{array}$ & Out_exp & $\begin{array}{l}\text { The logarithm of the per capita } \\
\text { expenditure in outpatient }\end{array}$ \\
\hline \multirow[t]{2}{*}{$\begin{array}{l}\text { Independent } \\
\text { variables }\end{array}$} & EPU & EPU1 & $\begin{array}{l}\text { China's provincial EPU index was } \\
\text { proposed by Yu et al. (28) }\end{array}$ \\
\hline & & EPU2 & $\begin{array}{l}\text { The standardization of China's } \\
\text { provincial EPU index was } \\
\text { proposed by Yu et al. (28) }\end{array}$ \\
\hline \multirow{8}{*}{$\begin{array}{l}\text { Control } \\
\text { variables }\end{array}$} & GDP & $G D P$ & The logarithm of GDP \\
\hline & Aging rate & Aging_rate & $\begin{array}{l}\text { The ratio of people over } 65 \text { to } \\
\text { the total population }\end{array}$ \\
\hline & $\begin{array}{l}\text { Urbanization } \\
\text { level }\end{array}$ & Urban_rate & $\begin{array}{l}\text { The ratio of the urban population } \\
\text { to the total population }\end{array}$ \\
\hline & $\begin{array}{l}\text { Industrial } \\
\text { structure }\end{array}$ & Indu_rate & $\begin{array}{l}\text { The proportion of the third } \\
\text { industry in the economic } \\
\text { structure }\end{array}$ \\
\hline & Mortality rate & Mor_rate & $\begin{array}{l}\text { The ratio of the deaths to the } \\
\text { total population }\end{array}$ \\
\hline & $\begin{array}{l}\text { Number of } \\
\text { medical } \\
\text { institutions }\end{array}$ & Hos_num & $\begin{array}{l}\text { The logarithm of the total } \\
\text { number of medical institutions }\end{array}$ \\
\hline & Fiscal revenue & Fiscal_rev & $\begin{array}{l}\text { The logarithm of the total number } \\
\text { of government fiscal revenue }\end{array}$ \\
\hline & $\begin{array}{l}\text { Number of } \\
\text { beds in medical } \\
\text { institutions }\end{array}$ & Bed_num & $\begin{array}{l}\text { The logarithm of the total } \\
\text { number of beds in medical } \\
\text { institutions per } 10,000 \text { people }\end{array}$ \\
\hline
\end{tabular}

is measured by the proportion of the third industry in the economic structure. The mortality rate is measured by the ratio of the deaths to the total population. The number of medical institutions is measured by the logarithm of the total number of medical institutions. The fiscal revenue is measured by the logarithm of the total number of government fiscal revenue. The number of beds in medical institutions is measured by the logarithm of the total number of beds in medical institutions per 10,000 people.

All variables and their definitions are given in Table 1, and their descriptive statistics are presented in Table 2.

\section{Methods}

\section{Spatial Autocorrelation Test}

Exploratory spatial data analysis (ESDA) is usually used to carry out the spatial autocorrelation test (39). Hence, we adopt the global and the local Moran index in ESDA to test the spatial correlation. The calculation formulas are as follows:

$$
\begin{gathered}
I_{\text {global }}=\frac{\sum_{i=1}^{n} \sum_{j=1}^{n} w_{i j}\left(x_{i}-\bar{x}\right)\left(x_{j}-\bar{x}\right)}{S^{2} \sum_{i=1}^{n} \sum_{j=1}^{n} w_{i j}} \\
I_{\text {local }}=\frac{\left(x_{i}-\bar{x}\right)}{S^{2}} \sum_{j=1}^{n} w_{i j}\left(x_{j}-\bar{x}\right)
\end{gathered}
$$

TABLE 2 | Descriptive statistics of all variables.

\begin{tabular}{lrrrrr}
\hline Variables & Obs & Mean & S.D. & \multicolumn{1}{c}{ Min } & Max \\
\hline In_exp & 319 & 72.750 & 31.410 & 29.290 & 217.400 \\
Out_exp & 319 & 1.676 & 0.745 & 0.010 & 4.602 \\
EPU1 & 319 & 4.444 & 0.478 & 1.411 & 6.051 \\
EPU2 & 319 & 21.220 & 14.760 & 1.010 & 86.250 \\
GDP & 319 & 9.537 & 0.876 & 6.681 & 11.400 \\
Aging_rate & 319 & 9.688 & 1.905 & 5.473 & 14.410 \\
Urban_rate & 319 & 54.190 & 13.670 & 28.240 & 89.600 \\
Indu_rate & 319 & 42.970 & 9.279 & 28.300 & 80.560 \\
Mor_rate & 319 & 5.737 & 1.103 & 2.280 & 7.400 \\
Hos_num & 319 & 2.759 & 0.720 & 0.470 & 4.069 \\
Fiscal_rev & 319 & 6.935 & 0.966 & 3.768 & 9.091 \\
Bed_num & 319 & 9.932 & 0.896 & 7.333 & 11.310 \\
\hline
\end{tabular}

where, $\bar{x}=\frac{1}{n} \sum_{i=1}^{n} x_{i}, S^{2}=\frac{1}{n} \sum_{i=1}^{n}\left(x_{i}-\bar{x}\right)^{2} ; I_{\text {global }}$ and $I_{\text {local }}$ represent the global Moran index and local Moran index, respectively; $x_{i}$ and $x_{j}$ are the observed variables of region $i$ and region $j$, respectively; $\bar{x}$ is the mean value of the related variable; $S^{2}$ is the variance of the related variable; $n$ is the total number of regions; $w_{i j}$ is the element of the spatial weight matrix.

Furthermore, it is essential to construct spatial weighting matrices to describe the relationship between different regions. In this study, referring to the study of Zeng et al. (27), we construct three spatial weight matrices (including spatial contiguity weight matrix, spatial distance weight matrix, and spatial economic weight matrix) to examine the spatial effects of EPU on healthcare expenditure.

The spatial contiguity weight matrix (W1) is constructed as follows:

$$
w_{i j}=\left\{\begin{array}{l}
1, i \neq j \\
0, i=j
\end{array} i, j=1,2, \ldots, n\right.
$$

Besides, we construct the spatial distance weight matrix W2 to conduct the empirical analysis. The spatial distance weight matrix $\mathrm{W}_{2}$ is constructed as follows:

$$
w_{i j}=\left\{\begin{array}{l}
1 / d_{i j}, i \neq j \\
0, i=j
\end{array} \quad i, j=1,2, \ldots, n\right.
$$

Where, $d_{i j}$ is the road distance between region $i$ and region $j$.

However, the above two spatial weight matrixes only reflect the geographical relationship between regions, but they cannot reflect the influence of other factors (27). Hence, we also construct the spatial economic weight matrix W3 as follows:

$$
W_{3}=W_{1} * \frac{1}{\bar{Y}} \operatorname{diag}\left(\overline{Y_{1}}, \overline{Y_{2}}, \mathrm{~L}, \overline{Y_{n}}\right), i, j=1,2, \ldots, n
$$

Where $\overline{Y_{i}}=\frac{1}{t_{1}-t_{0}+1} \sum_{t=t_{0}}^{t_{1}} Y_{i t}, Y=\frac{1}{n} \sum_{i=1}^{n} \overline{Y_{i}} ; Y_{i t}$ is the per capita real GDP of the region $i$ at year $t$; $\bar{Y}_{i}$ is the average per capita real GDP of the region $i$ over the years; $Y$ is the average per capita real GDP in all regions over the years. 


\section{Models}

Prior literature mainly uses the three spatial econometric models, such as the spatial autoregression model (SAR), spatial errors model (SEM), and spatial Durbin model (SDM), to investigate the spatial effects between the related variables (40). Among them, SAR only contains the lagged term of dependent variables, SEM only contains the spatial spillover effects of independent variables, while SDM contains both the lagged term of dependent variables and the spatial spillover effects of independent variables. The above three spatial econometric models are defined as follows:

$$
\begin{aligned}
Y_{i t} & =\alpha+\rho W * Y_{i t}+\alpha_{1} E P U_{i t}+\beta \text { Control }_{i t}+\sigma W * X_{k i t} \\
& +\mu_{i t} \\
u_{i t} & =\lambda W u_{i t}+\varepsilon_{i t}, \varepsilon \sim N\left(0, \sigma^{2} I_{n}\right)
\end{aligned}
$$

Where $Y_{i t}$ represents the dependent variable of health expenditure; $E P U_{i t}$ represents the independent variable of

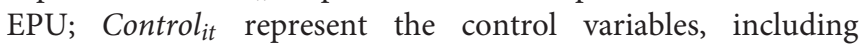
GDP, Aging_rate, Urban_rate, Indu_rate, Mor_rate, Hos_num, Fiscal_rev, and Bed_num, respectively; $X$ includes independent variable and control variables; $\mathbf{W}$ represents the spatial weight matrix; $\alpha$ represents the intercept item; $\alpha_{1}$ represents the coefficient of independent variable; $\beta$ represents the coefficient of control variables; $\rho$ represents the spatial autoregressive coefficient; $\lambda$ represents the spatial error coefficient; $\theta$ represents the spatial lag coefficient. When $\rho \neq 0$ and $\lambda=\theta=0$, the model is SAR; $\lambda \neq 0$ and $\rho=\theta=0$, the model is SEM; when $\rho \neq 0, \theta \neq 0$, and $\lambda=0$, the model is SDM.

\section{Model Selection}

Consistent with the prior literature, we also use the Lagrange multiplier tests (i.e., LM-lag and LM-err) to select the spatial econometric model (41). The results are given in Table 3. All the results (including LM lag test, robust LM lag test, LM error test, and robust LM error test) are all significant at the 5\% level, thus we should reject the null hypothesis of "no spatial autocorrelation." Besides, the results of the Wald test and LR test are all significant at the $1 \%$ level. The above results indicate that we should apply the spatial econometric models to investigate the impact of EPU on healthcare expenditure in China. Because SDM includes both the lagged term of dependent variables and the spatial spillover effects of independent variables, we should select SDM for empirical analysis.

\section{SPATIAL AUTOCORRELATION ANALYSIS}

We apply the Moran index to perform the spatial autocorrelation analysis. When the value of the Moran index is greater than zero, it indicates that there is a positive spatial correlation between data. On the contrary, when the value of the Moran index is smaller than zero, it indicates that there is a negative spatial correlation between data. The values of the global Moran index for the main variables are reported in Table 4 . The results show that all the Moran index values of In_exp and Out_exp are positive and significant at the $5 \%$ level based on the two spatial matrices. These indicate that healthcare expenditure has obvious
TABLE 3 | Model selection test.

\begin{tabular}{lcc}
\hline Tests & $\boldsymbol{t}$-statistics & $\boldsymbol{p}$-values \\
\hline LM (lag) test & 9.680 & 0.002 \\
Robust LM (lag) test & 5.683 & 0.017 \\
LM (error) test & 10.044 & 0.002 \\
Robust LM (error) test & 6.046 & 0.014 \\
Wald test spatial lag & 85.136 & 0.000 \\
LR test spatial lag & 37.666 & 0.000 \\
Wald test spatial error & 85.175 & 0.000 \\
LR test spatial error & 37.702 & 0.000 \\
\hline
\end{tabular}

spatial autocorrelation in different regions of China. For EPU, some of their Moran index values are significant at the $10 \%$ level, which suggests that EPU of different regions is also spatial correlated with other regions.

We also use the local Moran index to examine the local agglomeration characteristics of healthcare expenditure and EPU. In the scatter plots of the local Moran index, the first quadrant and the third quadrant represent high-high $(\mathrm{H}-\mathrm{H})$ value clustering and low-low (L-L) value clustering, respectively. The second quadrant and the fourth quadrant represent lowhigh (L-H) value clustering and high-low (H-L) value clustering, respectively. Figure 3 gives the scatter plots of Moran index value using the spatial contiguity matrix W1 in 2017. We can find that, for healthcare expenditure (In_exp and Out_exp), most regions are located in the first quadrant and the third quadrant. These results suggest that healthcare expenditure has a positive spatial correlation with different regions. However, for the Moran index values of EPU (EPU1 and EPU2), most regions are located in the second quadrant and the fourth quadrant, which indicates that EPU has a negative spatial correlation in the different regions. These results are consistent with the global Moran index values in the above analysis. Therefore, it is necessary to consider spatial correlation when studying the impact of EPU on healthcare expenditure in China. Otherwise, the results may be biased.

\section{EMPIRICAL ANALYSIS AND DISCUSSION}

\section{Baseline Regression}

We carry out the empirical analysis based on three spatial weight matrices (including spatial contiguity weight matrix W1, spatial distance weight matrix W2, and spatial economic weight matrix W3). Table 5 reports the estimation results using the SDM method. Among them, Column (1) is the estimation results based on the spatial contiguity weight matrix W1, Column (2) is the estimation results based on the spatial distance weight matrix W2, and Column (3) is the estimation results based on the spatial contiguity weight matrix W3.

The spatial autoregressive coefficients $\rho$ are all positive and significant at the $10 \%$ level based on the three spatial weight matrices. These results indicate that there are spatial spillover effects of healthcare expenditure between a given region and geographically or economically connected regions. In other words, healthcare expenditure is influenced not only by factors such as EPU in a given region but also by healthcare 
TABLE 4 | Global moran index values of healthcare expenditure and EPU.

\begin{tabular}{|c|c|c|c|c|c|c|c|c|}
\hline Year & \multicolumn{4}{|c|}{ Spatial contiguity weight matrix W1 } & \multicolumn{4}{|c|}{ Spatial economic weight matrix W3 } \\
\hline 2008 & $0.280^{\star \star \star}$ & $0.235^{\star \star \star}$ & -0.033 & $0.115^{*}$ & $0.373^{\star \star \star}$ & $0.29^{\star \star \star}$ & $-0.123^{\star}$ & -0.028 \\
\hline 2009 & $0.274^{\star \star \star}$ & $0.234^{\star \star \star}$ & 0.021 & -0.003 & $0.369^{\star \star \star}$ & $0.287^{\star \star \star}$ & $0.053^{\star}$ & 0.035 \\
\hline 2010 & $0.271^{\star \star \star}$ & $0.228^{\star \star \star}$ & -0.065 & -0.163 & $0.379^{\star \star \star}$ & $0.316^{\star \star \star}$ & -0.062 & -0.009 \\
\hline 2012 & $0.251^{\star \star \star}$ & $0.188^{\star \star}$ & 0.001 & $0.123^{\star}$ & $0.360^{\star \star \star}$ & $0.252^{\star \star \star}$ & 0.05 & $0.127^{\star \star}$ \\
\hline 2013 & $0.252^{\star \star \star}$ & $0.175^{\star \star}$ & $0.115^{\star}$ & $0.178^{\star \star}$ & $0.359^{\star \star \star}$ & $0.239^{\star \star \star}$ & $0.108^{\star \star}$ & $0.105^{\star}$ \\
\hline 2014 & $0.258^{\star \star *}$ & $0.149^{\star \star \star}$ & -0.101 & -0.031 & $0.362^{\star \star \star}$ & $0.215^{\star \star \star}$ & -0.033 & 0.000 \\
\hline 2015 & $0.263^{\star \star \star}$ & $0.151^{\star *}$ & -0.076 & 0.008 & $0.363^{\star \star \star}$ & $0.227^{\star \star \star}$ & -0.045 & 0.037 \\
\hline 2016 & $0.260^{\star \star \star}$ & $0.143^{\star \star}$ & $0.221^{\star \star \star \star}$ & -0.079 & $0.363^{\star \star \star}$ & $0.228^{\star \star \star}$ & -0.059 & -0.051 \\
\hline 2017 & $0.266^{\star \star \star}$ & $0.207^{\star \star}$ & -0.089 & -0.062 & $0.360^{\star \star \star}$ & $0.210^{\star \star \star}$ & -0.083 & -0.114 \\
\hline
\end{tabular}

${ }^{\star \star *} p<1 \%,{ }^{* *} p<5 \%$, and ${ }^{*} p<10 \%$.

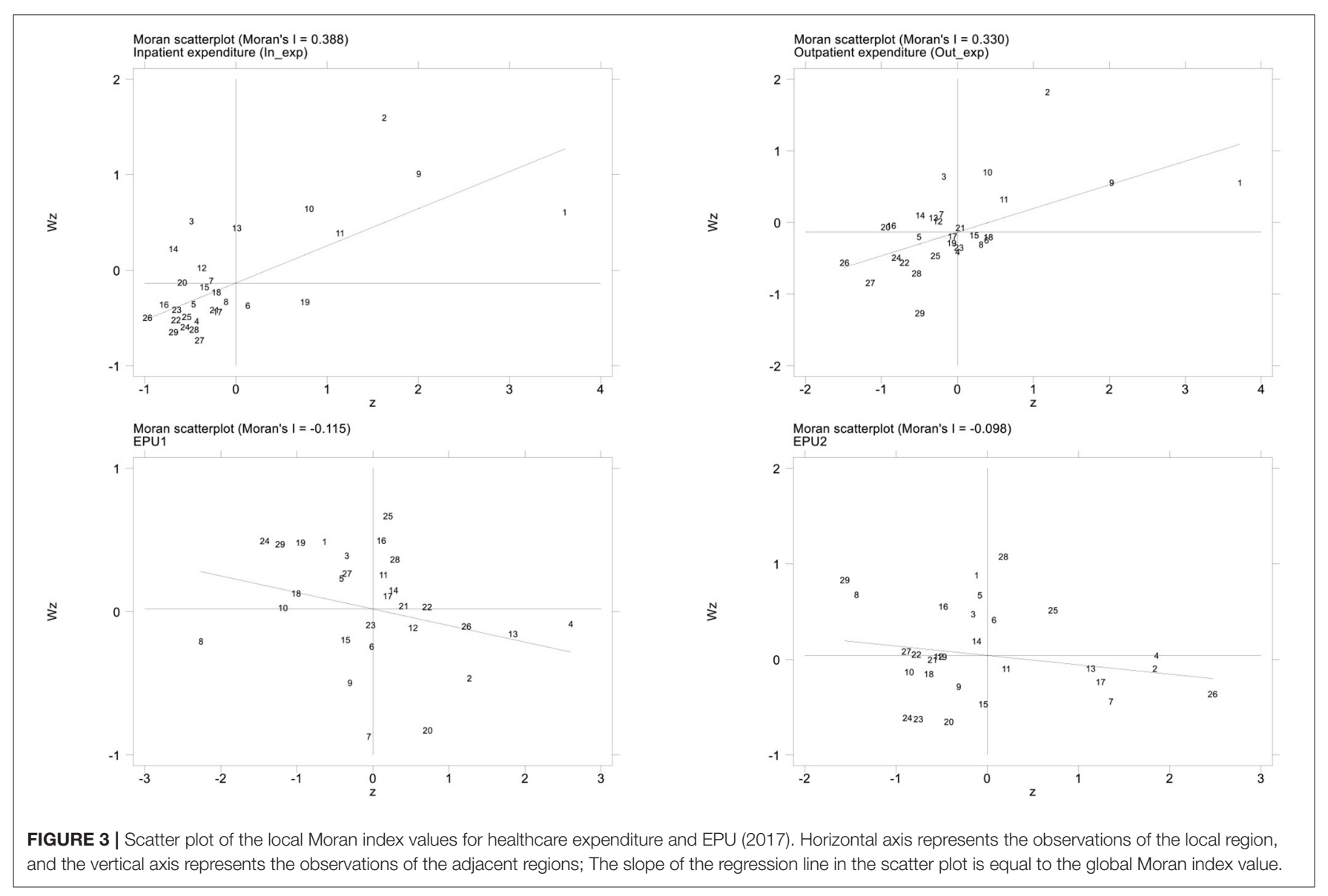

expenditure in neighboring or economically connected regions. These conclusions are consistent with the findings of Zeng et al. (27). For the spatial lag coefficients $\theta$, all the coefficients are significant at the $1 \%$ level, indicating that factors such as the EPU can affect healthcare expenditure not only in the given region itself but also in other nearby or economically connected regions. The coefficients of sigma2_e are all also significant at the $5 \%$ level. All these results suggest that there are spatial spillover effects between EPU and healthcare expenditure in China. Therefore, it is indispensable to introduce the spatial spillover effects when exploring the impact of EPU on healthcare expenditure. Otherwise, the conclusions will be biased. 
TABLE 5 | Estimation results of the impact of EPU on healthcare expenditure.

\begin{tabular}{|c|c|c|c|}
\hline \multirow[t]{2}{*}{ Variables } & $\begin{array}{c}\text { Contiguity weight } \\
\text { matrix W1 }\end{array}$ & $\begin{array}{l}\text { Distance weight } \\
\text { matrix W2 }\end{array}$ & $\begin{array}{c}\text { Economic weight } \\
\text { matrix W3 }\end{array}$ \\
\hline & (1) & (2) & (3) \\
\hline \multirow[t]{2}{*}{ EPU1 } & $0.9747^{\star \star \star}$ & $1.1836^{\star \star \star}$ & $1.1370^{\star \star \star}$ \\
\hline & $(3.16)$ & (3.83) & (3.11) \\
\hline \multirow[t]{2}{*}{ GDP } & 10.9685 & $16.4508^{\star \star}$ & $7.4569^{\star}$ \\
\hline & $(1.21)$ & $(2.08)$ & (1.73) \\
\hline \multirow[t]{2}{*}{ Aging_rate } & -0.0720 & -0.3310 & 0.5088 \\
\hline & $(-0.20)$ & $(-0.96)$ & $(1.54)$ \\
\hline \multirow[t]{2}{*}{ Urban_rate } & $-1.6444^{\star \star \star}$ & $-1.5419^{\star \star \star}$ & $-0.8205^{\star \star \star}$ \\
\hline & $(-3.58)$ & $(-2.98)$ & $(-2.62)$ \\
\hline \multirow[t]{2}{*}{ Indu_rate } & 0.3598 & 0.3707 & $0.4048^{\star \star}$ \\
\hline & $(1.51)$ & $(1.61)$ & $(2.16)$ \\
\hline \multirow[t]{2}{*}{ Death_rate } & 1.5551 & 0.3055 & -0.3009 \\
\hline & $(1.52)$ & (0.29) & $(-0.34)$ \\
\hline \multirow[t]{2}{*}{ Hos_num } & $-24.8311^{\star \star \star}$ & $-29.6151^{\star \star \star}$ & $-29.4146^{\star \star \star}$ \\
\hline & $(-2.64)$ & $(-2.96)$ & $(-3.95)$ \\
\hline \multirow[t]{2}{*}{ Fiscal_rev } & 8.6466 & 8.6837 & $14.0025^{\star \star \star}$ \\
\hline & $(1.60)$ & $(1.55)$ & (2.97) \\
\hline \multirow[t]{2}{*}{ Bed_rate } & 1.0982 & 0.0268 & 0.9478 \\
\hline & $(0.54)$ & $(0.01)$ & $(0.42)$ \\
\hline \multirow[t]{2}{*}{ _cons } & $-2.8 \mathrm{e}+02^{\star \star \star}$ & $-3.0 e+02^{\star \star \star}$ & $-3.6 e+02^{\star \star \star}$ \\
\hline & $(-5.61)$ & $(-5.12)$ & $(-5.86)$ \\
\hline \multirow[t]{2}{*}{$W^{*} E P U 1$} & -0.6815 & $5.4321^{\star \star \star}$ & $1.8449^{*}$ \\
\hline & $(-1.04)$ & (3.18) & $(1.85)$ \\
\hline \multirow[t]{2}{*}{$W^{*} G D P$} & $30.8799^{\star \star}$ & 11.5531 & $45.0768^{\star \star \star}$ \\
\hline & (2.32) & $(0.93)$ & $(4.02)$ \\
\hline \multirow[t]{2}{*}{$W^{*}$ Aging_rate } & 0.4442 & $2.5889^{\star \star}$ & 1.2100 \\
\hline & $(0.71)$ & (2.03) & $(1.05)$ \\
\hline \multirow[t]{2}{*}{ W*Urban_rate } & $1.2365^{\star \star}$ & 2.2339 & $-1.4553^{\star \star}$ \\
\hline & $(1.97)$ & $(1.47)$ & $(-2.46)$ \\
\hline \multirow[t]{2}{*}{$\mathrm{W}^{*} / n d u \_$rate } & $1.0346^{\star \star \star}$ & $1.7396^{\star \star \star}$ & $1.7709^{\star \star \star}$ \\
\hline & $(4.09)$ & (3.52) & $(4.77)$ \\
\hline \multirow[t]{2}{*}{$W^{*}$ Death_rate } & -1.5752 & -0.0983 & 0.6859 \\
\hline & $(-1.63)$ & $(-0.10)$ & $(0.82)$ \\
\hline \multirow[t]{2}{*}{$W^{*}$ Hos_num } & $-21.8530^{*}$ & $-70.4759^{\star \star}$ & $-51.3869^{\star \star \star}$ \\
\hline & $(-1.80)$ & $(-2.22)$ & $(-2.68)$ \\
\hline \multirow[t]{2}{*}{$W^{*}$ Fiscal_rev } & -6.9207 & 15.1669 & 0.0631 \\
\hline & $(-0.87)$ & $(1.61)$ & $(0.01)$ \\
\hline \multirow[t]{2}{*}{$W^{*}$ Bed_rate } & -0.2737 & 1.4840 & 0.7197 \\
\hline & $(-0.13)$ & $(0.70)$ & $(0.34)$ \\
\hline \multirow[t]{2}{*}{$\rho$} & $0.3945^{\star \star \star}$ & $0.3011^{*}$ & $0.5840^{\star \star \star}$ \\
\hline & (3.96) & (1.95) & (11.71) \\
\hline \multirow[t]{2}{*}{$\theta$} & $-3.1937^{\star \star \star}$ & $-3.3012^{\star \star \star}$ & $-2.7335^{\star \star \star}$ \\
\hline & $(-8.31)$ & $(-7.94)$ & $(-4.82)$ \\
\hline \multirow[t]{2}{*}{ sigma2_e } & $11.5810^{\star \star \star \star}$ & $11.7754^{\star \star \star}$ & $10.0067^{\star \star \star \star}$ \\
\hline & (8.73) & (8.25) & (9.32) \\
\hline Year FE & Yes & Yes & Yes \\
\hline Region FE & Yes & Yes & Yes \\
\hline$N$ & 319 & 319 & 319 \\
\hline
\end{tabular}

This table presents the regression results about the impact of EPU on healthcare expenditure using SDM method with time and entity fixed effects; ${ }^{* * *} p<1 \%$, ${ }^{* *} p<5 \%$, and ${ }^{*} p<10 \%$, respectively; $t$-statistics value in brackets.
The coefficients of EPU (EPU1) are all significant and positive at the $1 \%$ level (the coefficients are $0.9747,1.1836$, and 1.1370, respectively; the corresponding $t$-values are 3.16 , 3.83 , and 3.11 , respectively) when we apply for the three spatial weight matrices. It indicates that healthcare expenditure in a particular region is positively correlated with the EPU of the region. The possible reason is that with the increase of EPU, residents face greater psychological and life pressure, which increases the possibility of seeking medical treatment. More important, when EPU increases, the government may exert more expenditure on health, such as the COVID-19 outbreak in 2019. Furthermore, the coefficients of the spatial lag of EPU (W*EPU1) are positive and significant at the $1 \%$ level and the $10 \%$ level, respectively, when we use the spatial distance weight matrix W2 and spatial economic weight matrix W3. However, the coefficient is insignificant at the traditional statistical levels based on the spatial contiguity weight matrix W1. These results indicate that the increase of EPU in a given region has a positive impact on healthcare expenditure in geographically close or economically connected regions. We also find that the spatial effects of EPU on healthcare expenditure are more influenced by geographically close and economically connected regions.

For all the control variables, the direct coefficients $(G D P)$ and the spatial lag coefficients ( $W^{*} G D P$ ) of economic development are significantly positive at the traditional statistical levels, suggesting economic development in a region can increase the healthcare expenditure in a particular region or geographically close regions. The direct coefficients of urbanization level (Urban_rate) are negative and significant at the $1 \%$ level, indicating that urbanization is negatively related to healthcare expenditure in this region. The coefficients of the number of medical institutions (Hos_num and $\mathrm{W}^{*}$ Hos_num) are all significantly negative at the $1 \%$ level, suggesting that the increase in the number of medical institutions in the local or geographical close regions will reduce the healthcare expenditure. The possible reason is that an increase in the number of medical institutions would promote the degree of competition, and reduce the medical price, which in turn would lead to a reduction in healthcare expenditure.

\section{Decomposition Effects of EPU on Healthcare Expenditure}

The above conclusions show that there are significant spatial spillover effects in China's healthcare expenditure. Since SDM includes the spatial lag of dependent variables and independent variables at the same time, Lesage and Pace (42) decompose the total marginal effects into direct effects and indirect effects, which can better capture and explain the marginal effects of independent variables in SDM. Therefore, we further decompose the effects of EPU on healthcare expenditure (In_exp) into direct and indirect effects based on the spatial economic weight matrix W3, and the results are reported in Table 6.

It can be seen from the results in Table 6 that the coefficients of direct effects and indirect effects of EPU are 1.5158 and 5.8162 , respectively, and they are significant and positive at the $5 \%$ level. These results indicate that EPU not only promotes the 
TABLE 6 | Decomposition effects of EPU on healthcare expenditure.

\begin{tabular}{lccc}
\hline Variables & \multicolumn{3}{c}{ Dependent variable: In_exp } \\
\cline { 2 - 4 } & Direct effects & Indirect effects & Total effects \\
\hline EPU1 & $1.5158^{\star \star \star}$ & $5.8162^{\star \star}$ & $7.3321^{\star \star}$ \\
GDP & $(3.46)$ & $(2.21)$ & $(2.53)$ \\
& $14.4185^{\star \star \star}$ & $113.0735^{\star \star \star}$ & $127.4920^{\star \star \star}$ \\
Aging_rate & $(3.33)$ & $(3.95)$ & $(4.20)$ \\
& $0.7419^{\star \star}$ & 3.1982 & 3.9401 \\
Urban_rate & $(2.32)$ & $(1.23)$ & $(1.46)$ \\
& $-1.1047^{\star \star \star}$ & $-4.4539^{\star \star \star}$ & $-5.5586^{\star \star \star}$ \\
Indu_rate & $(-3.16)$ & $(-2.99)$ & $(-3.28)$ \\
& $0.6853^{\star \star \star}$ & $4.5839^{\star \star \star}$ & $5.2692^{\star \star \star}$ \\
Death_rate & $(3.63)$ & $(4.57)$ & $(4.88)$ \\
& -0.1546 & 1.1334 & $0.9788^{\star \star}$ \\
Hos_num & $(-0.18)$ & $(1.45)$ & $(2.14)$ \\
& $-39.0581^{\star \star \star}$ & $-1.5 e+02^{\star \star \star}$ & $-1.9 e+02^{\star \star \star}$ \\
Fiscal_rev & $(-3.81)$ & $(-2.64)$ & $(-2.87)$ \\
& $15.0720^{\star \star \star}$ & 17.7925 & $32.8645^{\star}$ \\
Bed_rate & $(3.28)$ & $(1.15)$ & $(1.84)$ \\
& 1.3537 & 2.7435 & $4.0973^{\star \star \star}$ \\
& $(0.64)$ & $(1.32)$ & $(2.76)$ \\
\hline
\end{tabular}

${ }^{\star \star *} p<1 \%,{ }^{* \star} p<5 \%$, and ${ }^{*} p<10 \%$, respectively; $t$-statistics value in brackets.

local healthcare expenditure but also has positive spatial spillover effects on the healthcare expenditure in the spatially related regions. The economic development (GDP) and the industrial structure (Indu_rate) can promote healthcare expenditure in the local region and also has significant positive spatial spillover effects on healthcare expenditure of the economically connected regions. Urbanization level (Urban_rate) and the number of medical institutions (Hos_num) have negative spatial spillover effects on healthcare expenditure in economically connected regions. These findings further verify that EPU has spatial spillover effects on healthcare expenditure. It also indicates that using spatial econometric models to analyze the relationship between EPU and healthcare expenditure can avoid overestimating the direct effects and underestimating the spatial spillover effects.

\section{Furth Analysis: Regional Heterogeneity}

There are obvious differences between the marketization process in the eastern region and that in the central and western areas of China. Compared with the eastern region with a higher level of economic development and more perfect medical conditions, the central and western areas are relatively backward in economic and medical conditions, and their health investment and medical level are relatively low. Thus, with the dramatic changes of EPU, there may be significant differences in healthcare expenditure among the three regions. Therefore, we further investigate the spatial spillover effects of EPU on healthcare expenditure in the eastern, central, and western areas.

Following the scope defined in the Regional Development Plan approved by the state in China, we divide our samples
TABLE 7 | Estimation results of regional heterogeneity.

\begin{tabular}{|c|c|c|c|}
\hline \multirow[t]{2}{*}{ Variables } & Eastern area & Central area & Western area \\
\hline & (1) & (2) & (3) \\
\hline \multirow[t]{2}{*}{ EPU1 } & $0.0344^{* * *}$ & $0.0451^{*}$ & -0.0571 \\
\hline & (3.35) & $(1.71)$ & $(-1.22)$ \\
\hline \multirow[t]{2}{*}{$W^{\star} E P U 1$} & $0.0238^{* * *}$ & 0.0236 & 0.0762 \\
\hline & $(2.62)$ & $(1.56)$ & (1.03) \\
\hline Control variables & Yes & Yes & Yes \\
\hline \multirow[t]{2}{*}{$\rho$} & $0.1196^{\star \star \star}$ & $0.1202^{\star \star \star}$ & $-0.2151^{\star *}$ \\
\hline & $(3.60)$ & $(2.87)$ & $(-2.46)$ \\
\hline \multirow[t]{2}{*}{$\theta$} & $-4.4107^{\star \star \star}$ & $-1.6911^{\star \star \star}$ & $-3.1585^{\star \star \star}$ \\
\hline & $(-12.16)$ & $(-4.09)$ & $(-9.10)$ \\
\hline \multirow[t]{2}{*}{ sigma2_e } & $9.0678^{* \star *}$ & $5.3169^{\star \star \star}$ & $5.1230^{\star \star \star}$ \\
\hline & $(9.28)$ & (3.42) & (3.84) \\
\hline Year FE & Yes & Yes & Yes \\
\hline Region FE & Yes & Yes & Yes \\
\hline$N$ & 110 & 99 & 110 \\
\hline
\end{tabular}

This table presents the regression results of the SDM method based on spatial economic weight matrix; The results of control variables are consistent with those in Table 5, and we do not report them in this table due to space limitations; ${ }^{\star \star *} p<1 \%$, ${ }^{\star *} p<5 \%$, and ${ }^{*} p<10 \%$, respectively; $t$-statistics value in brackets.

into three areas: the eastern area contains 10 regions: Beijing, Tianjin, Hebei, Liaoning, Shanghai, Jiangsu, Zhejiang, Fujian, Shandong, and Guangdong. The central area includes nine regions: Heilongjiang, Jilin, Shanxi, Inner Mongolia, Anhui, Jiangxi, Henan, Hubei, and Hunan. The western area consists of 10 regions: Guangxi, Chongqing, Sichuan, Guizhou, Yunnan, Shaanxi, Gansu, Qinghai, Ningxia, and Xinjiang. We conduct the regression estimation of regional heterogeneity using the SDM method, and the results based on the spatial economic weight matrix W3 are reported in Table 7 . We can find that all the spatial autoregressive coefficients $\rho$ in the eastern and central areas are significantly positive at the $1 \%$ level (their coefficients are 0.1196 and 0.1202 , respectively; the corresponding $t$-values are 3.60 and 2.87, respectively). In contrast, the spatial autoregressive coefficient $\rho$ is negative and significant at the $5 \%$ level in the west area. These results suggest that, to a certain extent, the spatial spillover effects of healthcare expenditure in the eastern and central areas are opposite to that in the western area. That is, healthcare expenditure in local regions has positive spatial spillover effects on geographically or economically similar regions in the eastern and central areas, while it has a negative spatial spillover effect in the western area. Besides, all the coefficients $\theta$ and sigma2_e are also significant at the $1 \%$ level, which further implies that there are spatial spillover effects of EPU on healthcare expenditure in the three areas.

In the eastern and central areas, the coefficients of EPU (EPU1) are significant and positive at the $1 \%$ level and the $10 \%$ level, respectively (the coefficients are 0.0344 and 0.0451 , respectively; the corresponding $t$-values are 3.35 and 1.71, respectively). However, its coefficients are negative but insignificant at the traditional statistical levels in the western 
TABLE 8 | Estimation results of robustness tests.

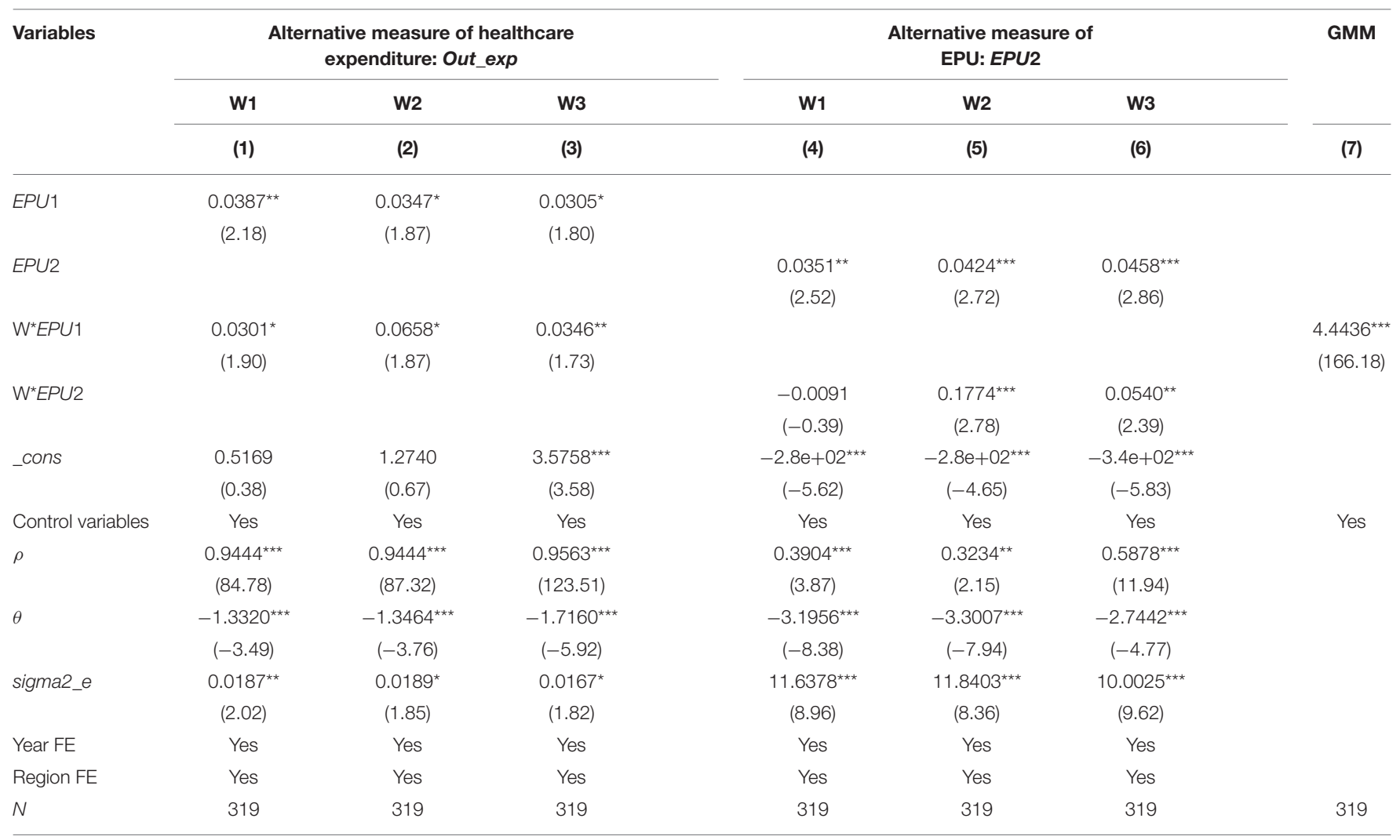

This table presents the robustness test results; Columns (1-3) are the results of the alternative measure of healthcare expenditure (Out_exp) based on the three spatial weight matrices, respectively; Columns (4-6) are the results of the alternative measure of EPU (EPU2) based on the three spatial weight matrices; Column (7) is the result of the endogenous test using the GMM method; The results of control variables are consistent with those in Table 5, and we do not report them in this table due to space limitations; ${ }^{* \star *} p<1 \%$, ${ }^{* *} p<5 \%$, and ${ }^{*} p<$ $10 \%$, respectively; t-statistics value in brackets.

area (the coefficient is -0.0571 , and the corresponding $t$ value is -1.22). The above results indicate that EPU has significant positive effects on healthcare expenditure in the eastern and central areas, while the effects are not significant in the western area. Next, focusing on the estimated coefficient of EPU ( $\left.\mathrm{W}^{*} E P U 1\right)$, it is positive and significant at the $1 \%$ level in the eastern area (the coefficient is 0.0238 , and the corresponding $t$-value is 2.62 ), but it is insignificant at the traditional statistical levels in the central and western areas. It implies that, in the eastern area, the increasing of EPU not only affects healthcare expenditure in the local region but also affects healthcare expenditure in geographically close or economically connected regions. However, the effects do not exist in the central and western areas.

\section{Robustness Tests}

\section{Alternative Measure of Healthcare Expenditure}

In the above analysis, we take inpatient expenditure (in_exp) as the proxy variable of healthcare expenditure. In this subsection, we adopt outpatient expenditure (out_exp) to conduct a robustness test for the above conclusions, and its definition is given in Section Variables. The results are reported in Columns (1-3) of Table 8. We can find that all the main coefficients (EPU1, $\mathrm{W}^{*} E P U 1, \rho, \theta$, sigma2_e) are consistent with the previous results. These empirical results further suggest that our empirical results remain stable when using different proxy variables.

\section{Alternative Measure of EPU}

In the above empirical tests, we use the EPU index proposed by $\mathrm{Yu}$ et al. (28) to measure the EPU. In this subsection, we adopt the standardization of China's provincial EPU index (EPU2) proposed by Yu et al. (28) to carry out the robustness test, and the definition of EPU2 is given in Section Variables. The regression results are reported in Columns (4-6) of Table 8 and show that all the coefficients are significant at the traditional statistical levels. These results suggest that our previous conclusions are robust, and further confirm that EPU has spatial spillover effects on healthcare expenditure in China.

\section{Endogenous Test}

In general, it is difficult for healthcare expenditure to affect EPU at the macro level. Thus, there is almost no inverse causality between EPU and healthcare expenditure. Besides, we control some related variables influencing healthcare expenditure in the previous empirical analyses, but it is impossible to avoid endogenous problems. Therefore, referring to the study of Elhorst (40), we use the spatial Generalized 
Method of Moments (GMM) to perform the endogenous test. Following Zeng et al. (27), we adopt $\mathrm{W}^{*} E P U 1$ as the instrumental variable of the spatial GMM method. The results of the spatial GMM method are reported in Column (7) of Table 8. The coefficient of $\mathrm{W}^{*} E P U 1$ is significant and positive at the $1 \%$ level, which further verifies the results of the spatial GMM estimation are consistent with the previous conclusions.

\section{CONCLUSIONS AND IMPLICATIONS}

This study aims to explore the impact of EPU on healthcare expenditure using the panel data of 29 Chinese regions from 2007 to 2017. Moreover, we also analyze the regional heterogeneity of the spatial effects between EPU and healthcare expenditure. For these purposes, we adopt the spatial Durbin model (SDM) to conduct empirical analyses based on the three spatial weight matrices.

This study is the first substantial research of the spatial spillover effects of EPU on healthcare expenditure in health economic studies. Our empirical results show that healthcare expenditure is not randomly distributed between regions in China, and has significant characteristics of spatial clustering and spatial spillover effects. In other words, local healthcare expenditure can exert positive spatial spillover effects on geographically or economically connected regions. We also find a positive correlation between EPU and healthcare expenditure. That is to say, EPU can affect healthcare expenditure not only in the local region itself but also in other geographically or economically connected regions. Moreover, our study further reveals that the above spatial spillover effects are heterogeneous in the eastern, central, and western areas. The spatial spillover effects of EPU on healthcare expenditure only exist in the eastern area, but not in the central and western areas.

\section{REFERENCES}

1. Crookes C, Palladino R, Seferidi P, Hirve R, Siskou O, Filippidis FT. Impact of the economic crisis on household health expenditure in Greece: an interrupted time series analysis. BMJ Open. (2020) 10:e038158. doi: 10.1136/bmjopen-2020-038158

2. Pu XH, Zeng M, Luo YL. The effect of business cycles on health expenditure: a story of income inequality in China. Front Public Health. (2021) 9:653480. doi: 10.3389/fpubh.2021.653480

3. Su CW, Huang SW, Tao R, Haris M. Does economic overheating provide positive feedback on population health? Evidence from BRICS and ASEAN countries. Front. Public Health. (2021) 9:661279. doi: $10.3389 /$ fpubh.2021.661279

4. Lee HJ, Lee DW, Choi DW, Oh SS, Kwon J, Park EC. Association between changes in economic activity and catastrophic health expenditure: findings from the Korea health panel survey, 2014-2016. Cost Eff Resour Alloc. (2020) 18:1-9. doi: 10.1186/s12962-020-00233-9

5. Hone T, Mirelman AJ, Rasella D, Paes-Sousa R, Barreto ML, Rocha $\mathrm{R}$, et al. Effect of economic recession and impact of health and social protection expenditures on adult mortality: a longitudinal analysis of 5565 Brazilian municipalities. Lancet Glob Health. (2019) 7:e1575-83. doi: 10.1016/S2214-109X(19)30409-7
Overall, our empirical findings highlight the spatial spillover effects of EPU on healthcare expenditure in emerging markets. However, there are some limitations in our study and further research is needed. First, the dataset of our study is limited to provincial data in China, which may limit the generality of the results. Future research can extend the dataset to the municipal level or even the county level to examine the spatial effects of EPU on healthcare expenditure. Second, due to the availability of data, our research only uses the three spatial weight matrices, further research can be extended to other weight matrices, such as the human resources weight matrix and public service weight matrix. Finally, one crucial future research is to investigate whether the COVID-19 pandemic affects the impact of EPU on healthcare expenditure because the COVID-19 pandemic led to unprecedented policy responses, such as lockdowns and stimulus packages $(23,43,44)$.

\section{DATA AVAILABILITY STATEMENT}

The original contributions presented in the study are included in the article/supplementary material, further inquiries can be directed to the corresponding author/s.

\section{AUTHOR CONTRIBUTIONS}

PB: conceptualization, writing-original draft, and software. YT: data collection, literature search, and writing-original draft. WZ: writing-reviewing and editing and supervision. MZ: data collection, literature search. All authors contributed to the article and approved the submitted version.

\section{FUNDING}

This work was supported by fundamental research funds for central universities in Sichuan University (skbsh2020-06).

6. Braendle $\mathrm{T}$, Colombier $\mathrm{C}$. What drives public health care expenditure growth? Evidence from Swiss cantons, 1970-2012. Health Policy. (2016) 120:1051-60. doi: 10.1016/j.healthpol.2016.07.009

7. Hartwig J, Sturm JE. Robust determinants of health care expenditure growth. Appl Econ. (2014) 46:4455-74. doi: 10.1080/00036846.2014.964829

8. Murthy VNR, Okunade AA. Determinants of US health expenditure: evidence from autoregressive distributed lag (ARDL) approach to cointegration. Econ Model. (2016) 59:67-73. doi: 10.1016/j.econmod.2016.07.001

9. Rana RH, Alam K, Gow J. Financial development and health expenditure nexus: a global perspective. Int J Finan Econ. (2021) 26:1050-63. doi: 10.1002/ijfe.1835

10. Qin X, Godil DI, Khan MK, Sarwat S, Alam S, Janjua L. Investigating the effects of COVID-19 and public health expenditure on global supply chain operations: an empirical study. Operat Manage Res. (2021). doi: 10.1007/s12063-020-00177-6. [Epub ahead of print].

11. Cheng CHJ, Witvorapong N. Health care policy uncertainty, real health expenditures and health care inflation in the USA. Empir Econ. (2019) 60:2083-103. doi: 10.1007/s00181-019-01818-x

12. Lago-Peñas S, Cantarero-Prieto $\mathrm{D}$, Blázquez-Fernández $\mathrm{C}$. On the relationship between GDP and health care expenditure: a new look. Econ Model. (2013) 32:124-9. doi: 10.1016/j.econmod.2013. 01.021 
13. Barati M, Fariditavana H. Asymmetric effect of income on the US healthcare expenditure: evidence from the nonlinear autoregressive distributed lag (ARDL) approach. Empir Econ. (2020) 58:1979-2008. doi: 10.1007/s00181-018-1604-7

14. You X, Okunade AA. Income and technology as drivers of Australian healthcare expenditures. Health Econ. (2017) 26:853-62. doi: 10.1002/hec.3403

15. Hyun KR, Kang S, Lee S. Population aging and healthcare expenditure in Korea. Health Econ. (2016) 25:1239-51. doi: 10.1002/hec.3209

16. de la Maisonneuve C, Moreno-Serra R, Murtin F, Martins JO. The role of policy and institutions on health spending. Health Econ. (2017) 26:834-43. doi: 10.1002/hec.3410

17. Jakovljevic M, Potapchik E, Popovich L, Barik D, Getzen TE. Evolving health expenditure landscape of the BRICS nations and projections to 2025. Health Econ. (2017) 26:844-52. doi: 10.1002/hec.3406

18. Kockaya G, Oguzhan G. Çalşkan Z. Changes in catastrophic health expenditures depending on health policies in Turkey. Front Public Health. (2020) 8:614449. doi: 10.3389/fpubh.2020.614449

19. Potrafke N. The growth of public health expenditures in OECD countries: do government ideology and electoral motives matter? J Health Econ. (2010) 29:797-810. doi: 10.1016/j.jhealeco.2010.07.008

20. Baker SR, Bloom N, Davis SJ. Measuring economic policy uncertainty. Q J Econ. (2016) 131:1593-636. doi: 10.1093/qje/qjw024

21. Lorenzoni L, Belloni A, Sassi F. Health-care expenditure and health policy in the USA versus other high-spending OECD countries. Lancet. (2014) 384:83-92. doi: 10.1016/S0140-6736(14)60571-7

22. Sun TT, Su CW, Mirza N, Umar M. How trade policy uncertainty affects agriculture commodity prices? Pac Basin Finan J. (2021) 66:101514. doi: 10.1016/j.pacfin.2021.101514

23. Zhang WK, Zhang XY, Tian XL, Sun FW. Economic policy uncertainty nexus with corporate risk-taking: the role of state ownership and corruption expenditure. Pacific-Basin Finance Journal. (2021) 66:101496. doi: 10.1016/j.pacfin.2021.101496

24. Tian XL, Kou G, Zhang WK. Geographic distance, venture capital and technological performance: evidence from Chinese enterprises. Technol Forecast Soc Change. (2020) 158:120155. doi: 10.1016/j.techfore.2020.1 20155

25. Zhang WK, Tian XL, Yu A. Is high-speed rail a catalyst for the fourth industrial revolution in China? Story of enhanced technology spillovers from venture capital. Technol Forecast Soc Change. (2020) 161:120286. doi: 10.1016/j.techfore.2020.120286

26. Anselin L, Griffith D. A. Do spatial effects really matter in regression analysis? Pap Reg Sci. (1988) 65:11-34. doi: 10.1111/j.1435-5597.1988.tb0 1155.x

27. Zeng M, Du J, Zhang W. Spatial-temporal effects of PM2.5 on health burden: evidence from China. Int J Environ Res Public Health. (2019) 16:4695. doi: 10.3390/ijerph16234695

28. Yu J, Shi XP, Guo DM, Yang LJ. Economic policy uncertainty (EPU) and firm carbon emissions: evidence using a China provincial EPU index. Energy Econ. (2021) 94:105071. doi: 10.1016/j.eneco.2020.105071

29. Chen M, Ruan LF, Zhu ZB, Sang FJ. Macro uncertainty, analyst performance, managerial ability. Euras Bus Rev. (2020) 10:333-53. doi: $10.1007 / \mathrm{s} 40821-020-00148-8$
30. Creal DD, Wu JC. Monetary policy uncertainty and economic fluctuations. Int Econ Rev. (2017) 58:1317-54. doi: 10.1111/iere.12253

31. Khan MA, Qin XZ, Jebran K. Uncertainty and leverage nexus: does trade credit matter? Euras Bus Rev. (2020) 10:355-89. doi: 10.1007/s40821-020-00159-5

32. Mumtaz H, Surico P. Policy uncertainty and aggregate fluctuations. J Appl Econometr. (2018) 33:319-31. doi: 10.1002/jae.2613

33. Julio B, Yook Y. Political uncertainty and corporate investment cycles. J Finan. (2012) 67:45-83. doi: 10.1111/j.1540-6261.2011.01707.x

34. Konstantakis KN, Papageorgiou T, Michaelides PG, Tsionas EG. Economic fluctuations and fiscal policy in Europe: a political business cycles approach using panel data and clustering (1996-2013). Open Econ Rev. (2015) 26:97198. doi: 10.1007/s11079-015-9345-0

35. Su CW, Huang SW, Qin M, Umar M. Does crude oil price stimulate economic policy uncertainty in BRICS? Pac Basin Finan J. (2021) 66:101519. doi: 10.1016/j.pacfin.2021.101519

36. Lee K, Jeon Y, Jo C. Chinese economic policy uncertainty and US households' portfolio decisions. Pac Basin Finan J. (2020) 64:101452. doi: 10.1016/j.pacfin.2020.101452

37. Nartea GV, Bai $\mathrm{H}, \mathrm{Wu}$ J. Investor sentiment and the economic policy uncertainty premium. Pac Basin Finan J. (2020) 64:101438. doi: $10.1016 /$ j.pacfin.2020.101438

38. Shen H, Liu R, Xiong H, Hou F, Tang XY. Economic policy uncertainty and stock price synchronicity: evidence from China. Pac Basin Finan J. (2021) 65:101485. doi: 10.1016/j.pacfin.2020.101485

39. Moran P. Notes on continuous stochastic phenomena. Biometrika. (1950) 37:17-23. doi: 10.1093/biomet/37.1-2.17

40. Elhorst JP. Spatial Econometrics: From Cross-Sectional Data to Spatial Panels. Heidelberg: Springer (2014).

41. Anselin L, Arribas-Bel D. Spatial fixed effects and spatial dependence in a single cross-section. Pap Reg Sci. (2013) 92:3-17. doi: 10.1111/j.1435-5957.2012.00480.x

42. Lesage JP, Pace RK. Introduction to Spatial Econometrics. Boca Raton, FL: Taylor \& Francis (2009). doi: 10.1201/9781420064254

43. Haldar A, Sethi N. The effect of country-level factors and government intervention on the incidence of COVID-19. Asian Econ Lett. (2020) 1:17804. doi: 10.46557/001c.17804

44. Stepovic M, Rancic N, Vekic B, Dragojevic-Simic V, Vekic S, Ratkovic N, et al. Gross domestic product and health expenditure growth in Balkan and East European countries-three-decade horizon. Front Public Health. (2020) 8:492. doi: $10.3389 /$ fpubh.2020.00492

Conflict of Interest: The authors declare that the research was conducted in the absence of any commercial or financial relationships that could be construed as a potential conflict of interest.

Copyright (c) 2021 Bai, Tang, Zhang and Zeng. This is an open-access article distributed under the terms of the Creative Commons Attribution License (CC BY). The use, distribution or reproduction in other forums is permitted, provided the original author(s) and the copyright owner(s) are credited and that the original publication in this journal is cited, in accordance with accepted academic practice. No use, distribution or reproduction is permitted which does not comply with these terms. 